\title{
Studi pharmacovigilance obat herbal di puskesmas X Yogyakarta
}

\author{
Mustika Muthaharah*1, Dyah Aryani Perwitasari ${ }^{2}$, Nyoman Kertia ${ }^{3}$ \\ ${ }^{1}$ Fakultas Farmasi, Universitas Muhammadiyah Banjarmasin \\ Jalan S. Parman. Kompleks RS Islam, Banjarmasin, Kalimantan Selatan 70114, Indonesia \\ ${ }^{2}$ Fakultas Farmasi, Universitas Ahmad Dahlan \\ Jl. Prof. Dr. Soepomo,S.H.,Janturan,Yogyakata \\ ${ }^{3}$ Program Pascasarjana \& Doktoral, Fakultas Kedokteran, Universitas Gadjah Mada, Yogyakarta \\ Bulaksumur, Caturtunggal, Kec. Depok, Kabupaten Sleman, Daerah Istimewa Yogyakarta 55281, \\ Indonesia
}

Submitted: 22-06-2016

Reviewed: 28-07-2016

Accepted: 28-03-2017

\begin{abstract}
ABSTRAK
Meningkatnya pengunaan obat herbal di masyarakat menyebabkan laporan terkait adverse event dan toksisitas juga meningkat. Adverse event dan toksisitas dapat dideteksi dengan sistem pharmacovigilance. Kejadian Adverse Drug Reaction (ADR) dari obat-obat herbal merupakan hal yang masih jarang diteliti di Indonesia sehingga diperlukan studi pharmacovigilance untuk mendeteksi kejadian ADR. Penelitian ini bertujuan untuk memberikan gambaran tentang kejadian ADR dari penggunaan obat herbal. Penelitian ini merupakan studi deskriptif dengan menggunakan data retrospektif pada pasien yang mendapat resep obat herbal di Puskesmas X Yogyakarta. Penelitian dilakukan dengan mengambil data pasien yang menggunakan obat herbal 10 bulan sebelum penelitian melalui rekam medik. Dilakukan wawancara untuk mengidentifikasi kejadian ADR kemudian dilakukan analisis kausalitas menggunakan algoritma Naranjo. Dari hasil penelitian diketahui bahwa $3(13,63 \%)$ dari 22 pasien mengalami ADR dengan kategori probabilitas probable (1) dan possible (2). Gejala ADR yang muncul adalah peningkatan frekuensi defekasi, penurunan konsistensi feces dan diuresis. Dari hasil penelitian dapat disimpulkan bahwa terdapat kejadian ADR pada pasien yang mendapat resep obat herbal di Puskesmas X Yogyakarta.
\end{abstract}

Kata kunci: ADR, obat herbal, pharmacovigilance

\begin{abstract}
The increasing usage of herbal medicine in community also intensify adverse event and toxicity report. Adverse events and toxicity can be detected with pharmacovigilance system. Adverse Drug Reaction (ADR) of herbal medicines is rarely studied in Indonesia. With the increasing use of herbal medicines in Indonesia, pharmacovigilance studies are necessary to detect the incidence of ADR. The purpose of this study is to describe the incidence of ADR on the use of herbal medicines. This research is a descriptive study using retrospective data. Research was conducted for 3 months by taking 10-month retrospective data using medical record. Interviews were conducted to identify the occurrence of ADR and assessment of quality of life using Naranjo algorithm.
\end{abstract}

Penulis korespondesi:

Mustika Muthaharah,

Fakultas Farmasi, Universitas Muhammadiyah Banjarmasin,

Jalan S. Parman. Kompleks RS Islam, Banjarmasin, Kalimantan Selatan 70114, Indonesia

Email: mmuthaharah@gmail.com 
The result showed that three (13.63\%) of 22 patients experiencing the ADR with probability of probable categories (1) and possible (2). The symptom of ADR that showed was the increased frequency of defecation, decreased in stool consistence and diuresis. The results of this study concluded that there are ADR event in patients who have been prescribed herbal medicine in Public Health Center X Yogyakarta.

Keywords: ADR, herbal medicine, pharmacovigilance.

\section{PENDAHULUAN}

Munculnya gaya hidup "Back to Nature", membuat masyarakat kembali memanfaatkan berbagai bahan alam, termasuk pengobatan dengan tumbuhan obat atau herbal sehingga penggunaan produk herbal dan obat-obatan herbal meningkat secara global. Obat herbal tidak selalu aman sekalipun terbuat dari bahan alami. Seiring dengan peningkatan penggunaan obat herbal, maka laporan terkait dugaan toksisitas dan adverse event juga meningkat sehingga diperlukan pemantauan keamanan pada obat-obatan herbal (Awodele et al., 2013 dan Debbie et al., 2012). Kegiatan yang berkaitan dengan deteksi, penilaian, pemahaman dan pencegahan efek samping atau masalah terkait obat disebut pharmacovigilance (WHO, 2002). Tujuan dari pharmacovigilance adalah untuk monitoring keamanan dan mendeteksi kejadian Adverse Drug Reaction (ADR) yang tidak terdeteksi sebelumnya saat eveluasi dan uji klinis (Awodele et al., 2013 dan Debbie et al., 2012).

Penelitian di berbagai negara melaporkan adanya kejadian ADR dari obat herbal dengan berbagai gejala dari ringan hingga berat termasuk diantaranya diare, mual dan penurunan berat badan (Awodele et $a l, 2013)$. ADR berat yang paling sering terjadi dalam kasus di seluruh dunia, adalah gangguan fungsi hati dan ginjal karena organ tersebut mendetoksifikasi dan mengekskresikan racun termasuk sisa metabolisme. Penelitian terbaru di Amerika Serikat yang dilaksanakan oleh Einstein Medical Center, Philadelphia, melaporkan bahwa penggunaan herbal dan suplemen makanan memiliki dampak yang buruk terhadap kualitas hidup konsumen karena dapat menyebabkan kerusakan hati yang irreversible (Debbie et al., 2012)

Di Nigeria dan Korea Selatan pelaporan terkait ADR dari obat herbal telah masuk ke dalam sistem pharmacovigilance Nasional. Penelitian terkait pharmacovigilance obat herbal dapat bersumber dari sistem pharmacovigilance Nasional. Hasil penelitian tentang ADR dari obat herbal juga dapat dilaporkan langsung ke sistem pharmacovigilance Nasional (Awodele et al., 2013 dan Shin et al., 2013). Di Indonesia penelitian tentang pharmacovigilance masih jarang dilakukan terlebih pharmacovigilance tentang obat herbal, sehingga perlu dilakukan penelitian untuk mengevaluasi aspek keamanan dari obat herbal dengan menggali data awal tentang kejadian ADR dari penggunaan obat herbal. Puskesmas X dipilih sebagai tempat penelitian karena Puskesmas ini sudah menerapkan pelayanan kesehatan berbasis pengobatan komplementer dengan meresepkan obat-obat herbal kepada pasien yang berobat ke Puskesmas X. Algoritma Naranjo dipilih sebagai instrumen untuk mengidentifikasi kejadian ADR karena lebih sistematis dan terstruktur sehingga memudahkan peneliti dalam melakukan identifikasi dan analisis kausalitas terkadap kemungkinan ADR yang muncul. Selain itu Algoritma Naranjo juga telah digunakan sebagai instrumen pada sistem pelaporan terkait Monitoring Efek Samping Obat (MESO) di Indonesia.

\section{METODE PENELITIAN}

Penelitian ini menggunakan data retrospektif dari pasien yang memperoleh resep obat herbal dari dokter di Puskesmas X Yogyakarta periode Januari sampai dengan Oktober Tahun 2015. Subjek penelitian ditentukan dengan kriteria inklusi sebagai berikut ; (1) Pasien laki-laki atau perempuan yang mendapat resep obat herbal berumur minimal 18 tahun (2) Pasien yang pernah mendapat resep obat herbal di Puskesmas X Yogyakarta periode Januari-Oktober 2015 (3) Menandatangani inform consent untuk ikut serta dalam penelitian. Subjek penelitian juga ditentukan berdasarkan kriteria eksklusi sebabagi berikut ; (1) Pasien tidak bersedia ikut dalam penelitian (2) Pasien meninggal dunia (3) Pasien dengan alamat yang tidak lengkap (4) Pasien pindah alamat (alamat baru tidak diketahui). Identitas pasien dikumpulkan melalui rekam medik. Pengambilan data dilakukan di kediaman pasien dengan metode wawancara. Kejadian ADR diidentifikasi menggunakan algoritma Naranjo. 
Analisis yang digunakan adalah analisis deskriptif univariat dan analisis kausalitas menggunakan algoritma Naranjo. Algoritma Naranjo terdiri dari 10 pertanyaan dengan 3 pilihan jawaban. Masingmasing jawaban memiliki skor tertentu. Skoring ADR dilakukan dengan menjawab pertanyaan tersebut. Skor dari setiap jawaban diakumulasi untuk memperoleh nilai skor total. Skor total tersebut digunakan untuk menentukan probabilitas dari kejadian ADR. Probabilitas kejadian ADR terbagi dalam 4 kategori berdasarkan rentang nilai skor total yang diperoleh yaitu ; definitely/sangat mungkin (skor $\geq 9$ ), possible/mungkin (skor 5-8), probable /cukup mungkin (skor 1-4) dan doubtful/diragukan (skor 0). Suatu kejadian merugikan akibat penggunaan obat dapat dinilai dari sudut pandang obat yang dikenal dengan istilah Adverse Drug Effect atau dari sudut pandang pasien yang dikenal dengan istilah Adverse Drug Reaction (ADR). Suatu kejadian ADR dapat berkaitan dengan efek farmakologi/mekanisme kerja (efek samping) ada pula yang tidak berkaitan dengan efek farmakologi (reaksi hipersensitivitas). Pada penelitian ini ADR didefinifikan sebagai kejadian atau kondisi yang merugikan, mengganggu dan tidak diharapkan berdasarkan sudut pandang pasien. Penelitian ini telah disetujui oleh Komite Etik Penelitian Universitas Ahmad Dahlan Yogyakarta.

\section{HASIL DAN PEMBAHASAN}

Dari 32 subjek yang memenuhi kriteria inklusi 10 diantaranya dieksklusi. Total subjek penelitian akhir yang mengikuti penelitian adalah 22 pasien. Tabel I menunjukkan karakteristik dari pasien yang memperoleh resep obat herbal. Mayoritas pasien pada penelitian ini didominasi oleh pasien perempuan (72\%). Berdasarkan umur didominasi oleh pasien berusia 60-85 tahun $(59,1 \%)$. Mayoritas merupakan pasien dengan tingkat pendidikan menengah $(45,5 \%)$ dan memiliki pekerjaan tetap serta penghasilan $(68,2 \%)$.

Tabel I. Data karakteristik pasien

\begin{tabular}{llcc}
\hline & Karakteristik Pasien & Jumlah (n) & Persentase (\%) \\
\hline Jenis kelamin & Laki-laki & 6 & $2,73 \%$ \\
\multirow{2}{*}{ Usia } & Perempuan & 16 & $72,7 \%$ \\
& $34-59$ tahun & 9 & $40,9 \%$ \\
Pendidikan & $60-85$ tahun & 13 & $59,1 \%$ \\
& Dasar & 7 & $31,8 \%$ \\
& Menengah & 10 & $45,5 \%$ \\
Pekerjaan & Tinggi & 5 & $22,7 \%$ \\
& Bekerja & 15 & $68,2 \%$ \\
Penghasilan & Tidak bekerja & 7 & $31,8 \%$ \\
& Berpenghasilan & 15 & $68,2 \%$ \\
& Tidak Berpenghasilan & 7 & $31,8 \%$ \\
\hline
\end{tabular}

Mayoritas pasien yang memilih menggunakan obat herbal adalah pasien wanita berusia antara 60 85 tahun. Sesuai dengan hasil Sensus Penduduk 2010 mayoritas jumlah penduduk secara umum dan penduduk dengan kelompok usia >60 di Daerah Istimewa Yogyakarta didominasi oleh penduduk wanita. Hal ini terkait dengan meningkatnya angka harapan hidup dari perempuan yang relatif lebih tinggi dari laki-laki disebabkan oleh kecenderungan penduduk laki-laki untuk melakukan pekerjaan dan aktivitas yang sifatnya lebih berat, kasar dan memiliki risiko lebih tinggi (Badan Pusat Statistik, 2014).

Hasil penelitian ini sejalan dengan penelitian oleh Mathew et al., 2010 yang menyebutkan bahwa faktor sosio-demografi yang berpengaruh dalam pemilihan penggunaan Complementary Alternative Medicine (CAM) adalah aspek jenis kelamin dan umur dimana CAM lebih banyak digunakan oleh pasien perempuan dibandingkan pasien laki-laki dan CAM kebanyakan digunakan oleh pasien dengan kategori usia dewasa tua daripada pasien dengan kategori usia muda dan paruh baya. 
Dari 22 orang pasien yang menjadi subjek penelitian diperoleh profil penyakit dan jenis obat herbal yang digunakan oleh pasien serta komposisi dari obat herbal yang digunakan. Informasi tersebut dapat dilihat pada Tabel II.

Berdasarkan hasil penelitian diketahui bahwa 6 dari 22 orang pasien pernah mengkonsumsi lebih dari satu jenis resep obat herbal baik dalam waktu yang bersamaan maupun tidak. Enam belas pasien lainnya tercatat hanya mengkonsumsi satu jenis resep obat herbal dengan rincian sebagai berikut; 3 pasien menggunakan jamu hipertensi, 3 pasien menggunakan jamu diabetes, 2 pasien menggunakan jamu kolesterol, 3 pasien menggunakan jamu analgetik anti-inflamasi, 1 pasien menggunakan jamu asma, 2 pasien menggunakan jamu diare dan 2 pasien menggunakan jamu batu ginjal.

Dari hasil penelitian yang dilakukan, teridentifikasi kejadian Adverse Drug Reaction (ADR) pada pasien yang mendapatkan resep obat herbal sebanyak 3 pasien (13,63\%) dari total 22 pasien. Pasien P2 mengalami ADR dengan gejala peningkatan frekuensi defekasi disertai penurunan konsistensi feces secara signifikan (cair). Pasien P13 mengalami penurunan konsistensi feces yang tidak signifikan (lembek). Pasien P22 mengalami gejala peningkatan frekuensi urinasi dan penurunan konsistensi feces tetapi tidak signifikan (lembek). Hasil analisis kausalitas dengan algoritma Naranjo ditunjukkan pada Tabel III

Tabel II. Profil penyakit, jenis obat herbal dan komposisi

\begin{tabular}{|c|c|c|c|c|}
\hline Penyakit & Jenis Obat herbal & Komposisi & $\begin{array}{c}\text { Jumlah Pasien } \\
\text { Pengguna (n) }\end{array}$ & Persentase (\%) \\
\hline $\begin{array}{l}\text { Diabetes } \\
\text { Mellitus }\end{array}$ & Jamu diabetes & $\begin{array}{l}\text { Daun sambiloto } \\
\text { Salam } \\
\text { Temulawak }\end{array}$ & 8 & $28,57 \%$ \\
\hline Hipertensi & Jamu hipertensi & $\begin{array}{l}\text { Daun seledri } \\
\text { Kumis kucing } \\
\text { Pegagan }\end{array}$ & 5 & $17,85 \%$ \\
\hline Hiperkolesterol & Jamu kolesterol & $\begin{array}{l}\text { Daun jati belanda } \\
\text { Daun kemuning } \\
\text { Kelembak } \\
\text { Tempuyung }\end{array}$ & 5 & $17,85 \%$ \\
\hline Batu ginjal & Jamu batu ginjal & $\begin{array}{l}\text { Daun kejibeling } \\
\text { Tempuyung } \\
\text { Alang-alang }\end{array}$ & 2 & $7,14 \%$ \\
\hline Nyeri sendi & $\begin{array}{c}\text { Jamu analgetik anti } \\
\text { infalamasi }\end{array}$ & $\begin{array}{l}\text { Temulawak } \\
\text { Kunyit } \\
\text { Meniran }\end{array}$ & 5 & $17,85 \%$ \\
\hline Asma & Jamu asma & $\begin{array}{l}\text { Daun Sembung } \\
\text { Kemukus } \\
\text { Cengkeh } \\
\text { Jahe }\end{array}$ & 1 & $3,57 \%$ \\
\hline Diare & Jamu diare & $\begin{array}{l}\text { Ekstrak Daun Jambu Biji } \\
\text { Ekstrak Kunyit } \\
\text { Ekstrak buah Mojokeling } \\
\text { Ekstrak kulit buah delima }\end{array}$ & 2 & $7,14 \%$ \\
\hline
\end{tabular}

Berdasarkan hasil analisis kausalitas dengan algoritma naranjo diketahui bahwa ADR yang dialami oleh pasien P2 termasuk dalam kategori probable dan ADR yang dialami oleh pasien P13 dan P22 termasuk dalam kategori possible. Berdasarkan pengertian ADR oleh BPOM (2012), ADR adalah suatu 
respon terhadap obat yang merugikan, tidak diinginkan atau tidak menyenangkan yang terjadi pada dosis terapi. maka ADR yang terjadi pada pasien tersebut termasuk kepada respon yang tidak menyenangkan atau tidak diinginkan berdasarkan pada sudut pandang pasien. Adverse Drug Reaction tidak hanya dilihat dari sudut pandang obat saja tetapi juga dari sudut pandang pasien. ADR yang dilihat berdasarkan sudut pandang pasien dikenal dengan sebutan Adverse Drug Effect ( Anonim, 2012).

Pada penelitian ini, ADR yang muncul merupakan suatu ADR yang dapat diprediksikan karena terkait dengan efek farmakologi dari sediaan jamu yang digunakan. Pada penelitian ini kejadian ADR dengan gejala peningkatan frekuensi defekasi dan penurunan konsistensi feses yang muncul pada pasien yang menggunakan obat herbal kemungkinan besar disebabkan karena efek dari akar kelembak. Akar kelembak mengandung zat tannin dan glikosida antrakinon yang memiliki efek laksatif (Bisset and Wichtl, 2001). Glikosida antrakinon merupakan glikosida larut air yang dapat meningkatkan kecepatan motilitas usus menghambat transit di usus besar. Penggunaan kelembak mentah dapat menyebabkan gangguan gastrointestinal termasuk nyeri perut, diare, mual dan muntah (Ulbritch and Seamon, 2010).

Terjadinya diuresis pada pasien P22 yang mengkonsumsi jamu kolesterol dan jamu hipertensi juga disebabkan karena efek farmakologi dari simplisia yang terkandung didalam sediaan. Jamu kolesterol mengandung tempuyung, jamu hipertensi mengandung seledri, daun kumis kucing dan pegagan. Keempat jenis simplisia tersebut semuanya diketahui memiliki aktifitas diuretik terutama tempuyung dan kumis kucing, keduanya memiliki efek diuretik kuat dan seringkali digunakan dalam pengobatan batu ginjal (Ahmed dan Abdul, 2010 : Brancović et al., 2010 : Imelda dan Andani, 2006 : Nurianti et al., 2014 : Roopesh et al., 2011). Penggunaan empat jenis simplisia yang memiliki efek diuretik secara bersama meningkatkan resiko terjadinya diuresis pada pasien sehingga pasien mengalami ADR dengan gejala diuresis.

Tabel III. ADR dan analisis kausalitas

\begin{tabular}{|c|c|c|c|c|}
\hline $\begin{array}{c}\text { Subjek } \\
\text { Penelitian }\end{array}$ & $\begin{array}{c}\text { Obat Herbal } \\
\text { yang dikonsumsi }\end{array}$ & Komposisi & Gejala ADR & $\begin{array}{c}\text { Analisis } \\
\text { Kausalitas }\end{array}$ \\
\hline $\mathrm{P} 2$ & Jamu Kolesterol & $\begin{array}{l}\text { Guazuma ulmifolia Lamk } \\
\text { Murraya paniculata [L.] } \\
\text { Jack. } \\
\text { Rheum officinale L. } \\
\text { Sonchus arvensis L. }\end{array}$ & $\begin{array}{l}\text { Peningkatan } \\
\text { frekuensi defekasi } \\
\text { \& penurunan } \\
\text { konsistensi feces }\end{array}$ & $\begin{array}{l}\text { Probable } \\
\text { (Mungkin) }\end{array}$ \\
\hline $\mathrm{P} 13$ & Jamu Kolesterol & $\begin{array}{l}\text { Guazuma ulmifolia Lamk } \\
\text { Murraya paniculata [L.] } \\
\text { Jack. } \\
\text { Rheum officinale L. } \\
\text { Sonchus arvensis L. }\end{array}$ & $\begin{array}{c}\text { Penurunan } \\
\text { konsistensi feces }\end{array}$ & $\begin{array}{c}\text { Possible } \\
\text { (Cukup Mungkin) }\end{array}$ \\
\hline $\mathrm{P} 22$ & $\begin{array}{l}\text { Jamu Hipertensi } \\
\text { Jamu Kolesterol }\end{array}$ & $\begin{array}{l}\text { Guazuma ulmifolia Lamk } \\
\text { Murraya paniculata [L.] } \\
\text { Jack. } \\
\text { Rheum officinale L. } \\
\text { Sonchus arvensis L. } \\
\text { Apium graviolens L. } \\
\text { Orthosiphon aristatus } \\
\text { Centella asiatica }\end{array}$ & $\begin{array}{c}\text { Diuresis \& } \\
\text { penurunan } \\
\text { konsistensi feces }\end{array}$ & $\begin{array}{c}\text { Possible } \\
\text { (Cukup Mungkin) }\end{array}$ \\
\hline
\end{tabular}

Penelitian yang dilakukan oleh Supari (2002) menunjukkan gejala ADR yang berbeda. ADR yang paling banyak terjadi pada penggunaan sediaan fitofarmaka seledri dan kumis kucing adalah rasa pusing dan tidak ditemukan efek samping peningkatan frekuensi urinasi. Hal ini mungkin saja terjadi mengingat 
perbedaan bentuk sediaan yang digunakan dalam penelitian. Selain itu pada penelitian tersebut hanya menggunakan 2 jenis simplisia yang memiliki khasiat diuretik sedangkan pada penelitian ini pasien mengkonsumsi 4 jenis simplisia yang memiliki khasiat diuretik sehingga meningkatkan resiko terjadinya diuresis.

Suatu ADR dapat diprediksikan kejadiannya apabila ADR tersebut terkait dengan dosis atau efek farmakologi obat (de Vries \& den Berg, 2001). Mengacu kepada pengertian serta tipe ADR oleh de Vries \& den Berg (2001) maka dapat disimpulkan bahwa ADR yang terjadi pada pasien P2, P13 dan P22 merupakan ADR tipe A yaitu ADR yang terkait dengan efek farmakologi dari obat.

Pada penelitian ini pasien P22 menggunakan obat kimia NSAID (natrium diklofenak) dan kortikosteroid (metilprednisolon) bersama dengan jamu kolesterol dan hipertensi. Staines (2011) dalam review artikelnya menyebutkan bahwa dapat terjadi interaksi antara obat kimia dengan obat herbal. Obat golongan NSAID berinteraksi dengan bawang putih, ginko dan feverfew. Obat golongan kortikosteroid dapat berinteraksi dengan licorice dan Echinacea. Abebe (2002) juga menyebutkan bahwa obat NSAID dapat berinteraksi dengan bawang putih, ginko, kunyit, jahe, ginseng dan asam jawa. Akan tetapi jamu yang digunakan pasien P22 tidak mengandung jenis herba yang dapat berinteraksi dengan obat golongan NSAID dan kortikosteroid sehingga kemungkinan terjadinya ADR akibat interaksi obat dapat dihindarkan.

Kebanyakan penelitian tentang interaksi antara obat kimia dengan obat herbal yang ada berdasarkan kepada laporan kasus individual, studi pada hewan dan data in-vitro sehingga diperlukan penelitian lebih lanjut untuk mengetahui potensi interkasi yang signifikan (Abebe, 2002).

\section{KESIMPULAN}

Terdapat $3(13,63 \%)$ kejadian ADR pada pasien yang mendapat resep obat herbal di Puskesmas X Yogyakarta. Berdasarkan analisis kausalitas menggunakan algoritma Naranjo diketahui bahwa pasien yang mendapat resep obat herbal di Puskesmas X Yogyakarta mengalami ADR dengan kategori probabilitas probable 1 pasien $(33,33 \%)$ dan possible 2 pasien $(66,67 \%)$ berdasarkan algoritma Naranjo serta kategori probabilitas certain (1 pasien) dan probable ( 2 pasien) berdasarkan kategori kausalitas WHO. Gejala ADR yang muncul adalah peningkatan frekuensi defekasi, penurunan konsistensi feces dan peningkatan frekuensi urinasi.

\section{UCAPAN TERIMAKASIH}

Terimakasih kepada seluruh staf Puskesmas X Yogyakarta dan seluruh pasien yang bersedia mengikuti penelitian ini.

\section{DAFTAR PUSTAKA}

Abebe, W., 2002, Herbal medication : Potential for adverse interaction with analgesic drugs, Journal of Clinical Pharmacy and Therapeutics (2002) 27, 392-401.

Ahamed, B.M , Abdul, M.A . Medicinal potentials of Orthosiphon stamineus Benth . Webmed Central CANCER 2010;1(12):WMC001361.

Anonim. 2012. Pedoman Monitoring Efek Samping Obat Bagi Tenaga Kesehatan. Badan POM RI. Jakarta.

Awodele, O., A. Daniel, T. D. Popoola, and E. F. Salami. 2013. "A Study on pharmacovigilance of herbal medicines in Lagos West Senatorial District, Nigeria." International Journal of Risk and Safety in Medicine 25(4):205-17.

Badan Pusat Statistik, Bidang Neraca Wilayah dan Analisis Statistik, 2014, Statistik Daerah Istimewa Yogyakarta, Yogyakarta : Badan Pusat Statistik Provinsi Daerah Istimewa Yogyakarta .

Bisset, N.G., Wichtl, M., 2001, Herbal Drugs and Phytopharmaceuticals : A Handbook for Practice on a Scientific Basis With Reference to German Commision E Monographs, Second Edition, CRC Press. 
Branković, S., Kitić, D., Radenković, M., Veljković, S., Kostić, M., Miladinović, B., Paviović, D., 2010, Hypotensive and cardioinhibitory effect of the aqueous and ethanol extract of celery (Apium graviolens, Apiaceae). Acta Medica Medianae, 49 (91): 13-16.

De Vries. C \& de Jong-van den Berg. L. 2001. Pharmacy Practice; Pharmacovigilance and Pharmacoepidemiology. CRC Press. Page; 337-355.

Debbie, S., Graeme, L., Pierre, D., Elizabeth, W., Kelvin, C. 2012. Pharmacovigilance of herbal medicine. Journal of Ethnopharmacology, 140(3);513-518 .

Imelda, E.R.F.B \& Andani, E.P. 2006. Perbandingan efek diuretika serta kadar natrium dan kalium darah antara pemberian ekstrak etanol daun tempuyung (Sonchus arvensis Linn) dengan furosemida. Jurnal Sains dan Teknologi Farmasi, 11(2) : 76-80.

Mathew, E., Muttappallymyalil, J., Sreedharan, J., John, L.J., John, J., et al, 2010, Self-reported use of complementary and alternative medicine among the health care consumers at a tertiary care center in Ajman United Arab Emirates, Annnals of Medical and Health Sciences Research 3(2): 215-219.

Nurianti,Y., Hendriani, R., Sukandar, E.Y., Anggadireja, K., 2014, Acute and subchronic oral toxicity studies of ethyl acetat extract of Sonchus Arvensis L. Leaves, International Jounal of Pharmacy and Pharmaceutical Science, 6(5):343-347.

Roopesh, C., Salomi, K.R., Nagarjuna, S., Reddy, Y.P., 2011, Diuretic activity of methanolic and ethanolic extract of Centella Asiatica leaves in rats, International Research Journal of Pharmacy, 2 (11), 163-165.

Shin, H.K., Jeong, S.J., Lee, M.S., Ernst E., 2013, Adverse events attributed to traditional Korean medical practices: 1999-2010, Bull World Health Organization, 91:569-575.

Staines, S.S., 2011, Herbal medicine : adverse effect and drug-herb interaction, Journal of the Malta Collage of Pharmacy Practice, 17;38-42.

Supari, F., 2002, Lowering blood pressure effect of Apium graviolens (seledri) and Orthosiphon stamineus Benth (kumis kucing) in mild and moderate hypertension. Medical Journal of Indonesia, 11:195-201.

Ulbritch, C.E., Seamon, E., 2010, Natural Standart Herbal Pharmacotherapy: An Evidance-based Approach, Mosby, Elsevier, Page: 186,340,551. 
